\title{
CITOLOGÍA ENDOMETRIAL DE TOMA DIRECTA. ESTUDIO COMPARATIVO
}

\author{
Diana Cruz Tovar; Sandra Liliana Garzón*
}

\section{Resumen}

El carcinoma endometrial se ha convertido en la lesión maligna más frecuente del cuerpo uterino. Se presentan anualmente 34.000 nuevos casos, de los cuales 6.000 ocasionan defunciones, lo que lo convierte en la séptima causa de muerte en mujeres; es más agresivo con el aumento de la edad. Es así como surge la idea de realizar un estudio cuidadoso con la citología endometrial de toma directa, que permita investigar y diagnosticar lesiones hormonales, premalignas y malignas del endometrio, y promueva la citología endometrial de toma directa como un métodode tamización para usar con mayor frecuencia en Colombia. También, demostrar que la interpretación de la citología endometrial tiene resultados tan satisfactorios como los de la biopsia y la pueden realizar citohistotecnólogos con un adecuadoentrenamiento.

Fueron estudiados 133 casos del Instituto Nacional de Cancerología (1999-2000), de los cuales sólo 123 fueron adecuados para lectura. A todos se les realizó un estudio citológico e histológico, con $94 \%$ de resultados benignos, $4,9 \%$ de resultados premalignos, y $\mathbf{0 , 8 \%}$ de malignidad en la citología. De estos casos el $88 \%$ se correlacionó con los resultados de la biopsia.

\section{Introducción}

El trabajo "modelo de interpretación de la citologia endometrial por toma directa" es una comparación de la toma directa de la citología endometrial con los resultados de la biopsia endometrial. Este se realizó obteniendo muestras citológicas con el cepillo, lo que permite mejor calidad en las muestras y detectar lesiones precancerosas, cancerosas, y estímulos hormonales del endometrio. Además, evita mayores molestias y tiene un precio más cómodo que la biopsia.

\section{Materiales y métodos}

El estudio se desarrolló en la consulta ginecológica del Instituto Nacional de Cancerología. La población abarcó las pacientes con indicación de biopsia endometrial, por lo regular para descartar lesiones premalignas y malignas. Se estudiaron 133 pacientes con citología endometrial previa a labiopsia de endometrio o a la histerectomía.

\footnotetext{
Citohistotecnólogas Fundación Universitaria de Ciencias de la Salud.
}

El instrumento utilizado fue un cepillo plástico con un dispositivo de camisa externa (tubo), en el cual se introduce el cepillo adaptado para el barrido de la cavidad endometrial, evitando así la contaminación.

\section{El procedimiento que se siguió fue:}

a. Observar la historia clínica: número del registro, peso, edad, talla, gestaciones, partos, diagnóstico clínico, edad de la menarquia, fecha de la última regla, uso o no de terapia hormonal y antecedentes clínicos.

1. Asignación de un número de protocolo a la paciente, igual al marcado en la lámina.

2. Se usaron las normas del sistema Bethesda para la clasificación.

- Muestra satisfactoria: cuando hay material suficiente para evaluar, es decir tiene mínimo 10 grupos celulares que tienen hasta 50 células, bien preservadas, no hemorrágica, fijación y coloración adecuada. 
- Muestra satisfactoriapero limitada: son aquellas que arrojan una información incompleta, o defectos en la fijación.

- Muestra inadecuada: son las que no se pueden leer por ser hemonágicas, contener escaso material (menos de I() agrupaciones por lámina), presentar contaminación cervicovaginal abundante, o por defectos en la fijación y la coloración.

4. Variables de características citológicas.

- Características de los agrupamientos:

1. La celularidad.

2. Tamaño de los agrupamientos.

3. Formas de agrupamientos.

- Evaluación de los núcleos.

- Disposición de los núcleos

-Evaluación de las células sueltas.

- Cantidad, uniformidad y atipia nuclear.

- Evaluación del fondo:

1. Inflamatorio.

2. Hemorragia.

3. Diátesis tumoral.

Toda esta información se recopiló en el informe de citología endometrial de toma directa.

\section{Resultados}

$56 \%$ de las láminas obtenidas fue adecuado para estudio, $36,5 \%$ satisfactorio y $7,5 \%$ inadecuado.
Al correlacionar la citología con la histología, 66 de los casos fueron proliferativos tanto en la citología como en la biopsia, 36 fueron secretores, 10 atrofias, 6 hiperplasias y 1 caso de malignidad.

Esto corresponde a un $88 \%$ de correlación de la citología con la biopsia.

\section{Discusión}

En el desarrollo de esta investigación, notamos que con el uso adecuado del cepillo de toma endometrial se obtiene una buena calidad de las muestras para detectar lesiones premalignas y malignas del endometrio. Estudios anteriores indicaban que lo adecuado era usar solo la biopsia, pero consideramos posible diagnosticar cualquiera de estas lesiones por los dos métodos, ya que arrojan resultados similares e igualmente confiables. Además, la citología endometrial de toma directa es un método sencillo, confiable, rápido y de bajo costo, con alta sensibilidad y especificidad, que cumple así con los requisitos para ser considerada como una prueba de tamización.

\section{Conclusiones}

Debido a la inapropiada utilización del cepillo de toma endometrial, hubo muestras inadecuadas para evaluación citológica. La citología endometrial de toma directa es un procedimiento confiable para diagnosticar lesiones de endometrio, al igual que la biopsia.

Se observó un al to índice de concordancia entre la biopsia y la citología endometrial de toma directa, lo que indica que puede ser utilizada como un método de tamización confiable. La interpretación de la citología endometrial de toma directa, con resultados satisfactorios, la pueden hacer los citólogos con un adecuado entrenamiento. 